\title{
In vitro and in vivo quality of bovine embryos in vitro produced with sex-sorted sperm
}

\author{
B. Trigal ${ }^{a}$, E. Gómez ${ }^{\mathrm{a}}$, J.N. Caamaño ${ }^{\mathrm{a}}$, M. Muñoz ${ }^{\mathrm{a}}$, J. Moreno ${ }^{\mathrm{b}}$, S. Carrocera ${ }^{\mathrm{a}}$, \\ D. Martín ${ }^{\mathrm{a}}$, C. $\operatorname{Diez}^{\mathrm{a}, 1, *}$ \\ a Área de Genética y Reproducción Animal, Centro de Biotecnología Animal, SERIDA, Gijón (Asturias), Spain \\ ${ }^{\mathrm{b}}$ Sexing Technologies, Navasota, TX, USA
}

Received 3 November 2011; received in revised form 7 June 2012; accepted 10 June 2012

\begin{abstract}
In this work we analyzed the effects of three culture systems on developmental ability of bovine embryos in vitro produced with sexed sperm, the survival to vitrification (cryologic vitrification method) of such blastocysts, and their pregnancy rates after embryo transfer to recipients, both as fresh and after vitrification/warming. Finally, we measured the accuracy of the sorting protocol by a polymerase chain reaction-based method to validate the embryo sex at blastocyst stages. We confirmed an individual effect of the bull as well as development rates of embryos produced with sorted sperm lower than embryos with unsorted sperm, independent of the culture system used. The cryoresistance to vitrification of embryos produced with sexed sperm did not differ from that of conventionally produced embryos (re-expansion rates at 24 and $48 \mathrm{~h}: 74.6 \%$ vs. $75.5 \%$, and $64.5 \%$ vs. $68.1 \%$ for embryos produced with conventional and sorted sperm, respectively; hatching rates at $48 \mathrm{~h}: 63.55 \%$ vs. $55.5 \%$ for embryos produced with conventional and sorted sperm, respectively). Finally, no significant differences were found in pregnancy rates after the embryo transfer of fresh and vitrified/warmed blastocysts (52.8\% vs. $42.0 \%$, respectively; $\mathrm{P}>0.05$ ). Male and female embryos produced with sorted sperm showed the same quality in terms of developmental ability, cryoresistance, and pregnancy rates after transfer. Our culture system, coupled with the vitrification in fiber plugs, provides good quality sex-known embryos which survive vitrification at similar rates than embryos produced with conventional unsorted sperm; also it produces good pregnancy rates after transfer of sexed embryos both fresh and after vitrification and warming.
\end{abstract}

(c) 2012 Elsevier Inc. All rights reserved.

Keywords: Sex-sorted sperm; In vitro production; Vitrification; Embryo transfer; Pregnancy

\section{Introduction}

The possibility of sex preselection has always generated great interest among livestock producers. Sexed semen can contribute to increase the profitability of the cattle industry through the production of offspring of the desired sex, such as females for dairy or males for

\footnotetext{
${ }^{1}$ Permanent address: CBA-SERIDA, Gijón (Asturias), Spain.

* Corresponding author. Tel.: +34 984502010; fax: +34 984502012.

E-mail address: mcdiez@serida.org (C. Diez).
}

meat production. Other applications would allow cattle breeders and artificial insemination (AI) semen companies to test elite bulls on small numbers of females [1].

Reliable sorting of X-and Y-bearing sperm through flow cytometry impacts selection schemes and enable the cattle industries to enhance and accelerate the diffusion of production traits [2]. After the development of the sperm sorting industry, sexed sperm has been used for AI, in vitro fertilization (IVF) and intracytoplasmic sperm injection in several species. However, reduced efficiency in the production of the embryos has been 
reported when using sexed sperm as compared with unsorted semen [for review, see 3]. Moreover, the sorting process is costly and has negative effects on quality of semen. Injuries have been reported because of the passage of semen by flow cytometry and laser incidence in DNA [4,5].

In vitro fertilization with sexed sperm has been approached with different sperm gradient separation techniques [6], modifying heparin concentrations, adding penicillamine, hipotaurine, and epinephrine (PHE) [7], or by means of new sperm cryopreservation procedures [8]. However, after fertilization with sex-sorted spermatozoa, lower fertility rates have been observed both in vivo [9-13] (after AI) and in vitro [14-16]. Thus, in a recent large field trial of AI using sexed spermatozoa from seven Holstein bulls, Frijters et al. [17] reported a $13.6 \%$ decline in the 56-day no return rate; many works also reported decreases in blastocysts rates after IVF of oocytes with sex-sorted sperm $[18,19]$. Proposed factors for the reduced fertility rates in vivo include not only the damage to the spermatozoa caused by the sorting procedure [11], but also the lower doses of spermatozoa used [9], and sire effects [20] (for review, see Rath et al. [21]).

Despite these data, IVF can increase the fertilization efficiency on a per spermatozoa basis [22]. In cattle, approximately 5000 unsorted sperm [23] and as few as 600 [24] or 1500 to 2250 sexed sperm [4] are sufficient to fertilize a bovine oocyte in vitro, whereas 20 million unsorted sperm [25] and 1 to 4 million of sorted and frozen sperm $[13,26]$ are normally used per AI. In vitro production (IVP) of embryos with sex-sorted sperm could justify the use of this sperm despite its higher price. Furthermore, we can increase the benefits of this technology by combining the use of sexed sperm in oocytes recovered by ovum pick-up [27] from donors previously superovulated, a treatment that improves the efficiency of the in vitro procedure compared with untreated donors [2].

After IVF and culture, the timing of both embryonic cleavage and blastocyst appearance has been reported to be altered when using sex-sorted spermatozoa [14]. Such parameters have been considered as embryo quality indicators. Moreover, ultrastructural studies showed that blastocysts produced with flow-cytometrically sexsorted spermatozoa have a lower quality than their nonsorted counterparts [19]. Puglisi and coworkers [6] described a minor tolerance of the sexed frozen-thawed sperm to the stress, making the manipulation procedures important during IVF. Although these kinetic and morphologic alterations may be responsible for the compromised development observed in embryos produced with sex-sorted spermatozoa, we could hypothesize that embryo development could be improved by using an optimized postfertilization culture.

Ultimately, a necessary step for the implementation of the production of sex-known calves by IVP is the development of an adequate cryopreservation protocol, allowing the storage of the produced embryos.

In the present study we analyzed the influence of three culture systems on blastocyst production with sexed sperm; we also tested the quality of the sexknown produced embryos in terms of survival to vitrification in fiber plugs (cryologic vitrification method; CVM) and their ability to establish pregnancies after embryo transfer to recipients, both fresh and after vitrification/warming. The accuracy of the sorting protocol was also evaluated by a polymerase chain reaction (PCR)-based method to validate the embryo sex.

\section{Materials and methods}

All chemicals were purchased from Sigma (Madrid, Spain), unless otherwise indicated.

\subsection{Collection of cumulus oocyte complexes}

Ovaries recovered from slaughtered cows were placed in $\mathrm{NaCl}$ solution $(9 \mathrm{mg} / \mathrm{mL})$ with antibiotics (penicillin, $100 \mathrm{IU} / \mathrm{mL}$ and streptomycin sulfate, 100 $\mathrm{mg} / \mathrm{mL}$ ) and maintained at $25{ }^{\circ} \mathrm{C}$ to $30{ }^{\circ} \mathrm{C}$ until cumulus oocyte complex (COC) collection. Follicles 2 to 7 $\mathrm{mm}$ in size were aspirated through an 18-ga needle connected to a syringe. Follicular fluid and COCs were rinsed three times in holding medium (HM) consisting of TCM199 (Invitrogen, Barcelona, Spain), $25 \mathrm{mM}$ HEPES and BSA $0.4 \mathrm{~g} / \mathrm{L}$ and matured in TCM199 NaHCO3 (2.2 g/L), fetal calf serum (FCS) (10\% vol/ vol), porcine FSH-LH (Stimufol, ULg FMV, Liège, Belgium) and $17 \beta$-estradiol $(1 \mu \mathrm{g} / \mathrm{mL})$. Only oocytes enclosed in a compact cumulus with an evenly granulated cytoplasm were selected for maturation and performed by culturing approximately 20 COCs in $400 \mu \mathrm{L}$ of maturation medium in four-well dishes at $39{ }^{\circ} \mathrm{C}$ in $5 \% \mathrm{CO}_{2}$ in air with high humidity for $22 \mathrm{~h}$.

\subsection{In vitro fertilization and culture}

Semen was provided by Sexing Technologies (Navasota, TX, USA). Purified sperm was sorted into X-bearing chromosome (female) and Y-bearing chromosome (male) populations by identifying differences between the $\mathrm{X}$ - and Y-bearing sperm. The difference in DNA contents between $\mathrm{X}$ - and Y-bearing sperm was used to sort sperma- 
tozoa with a flow cytometer. This technique is proven to be routinely $93 \%$ accurate in sorting.

Semen samples, sorted and unsorted, of 5 bulls were layered on a gradient consisting of $2 \times 700 \mu \mathrm{L}$ of Percoll (90\% and $45 \%$ ) (three straws containing $2.5 \times 10^{6}$ sperm per gradient for sexed sperm; one straw per gradient for conventional no sexed sperm), and centrifuged at $700 \mathrm{X} g$ for $15 \mathrm{~min}$. The supernatant was discarded and the pellet washed with $5 \mathrm{~mL}$ of Fert-TALP containing heparin and penicillamine $(2 \mathrm{mM})$, hypotaurine $(1 \mathrm{mM})$ and PHE $(250$ $\mu \mathrm{M})$. Heparin (Calbiochem, La Jolla, CA, USA) concentration (10 or $20 \mu \mathrm{g} / \mu \mathrm{L}$ ) was previously tested and adjusted for each bull as based on blastocyst development rates. After centrifugation $(10 \mathrm{~min}, 200 \mathrm{X} \mathrm{g}$ ) the resultant pellet was used for fertilization.

After in vitro maturation, COCs (in groups of 20) were washed twice in $\mathrm{HM}$, twice in pre-equilibrated Fert-TALP, and placed in $20-\mu \mathrm{L}$ droplets of Fert-TALP covered with mineral oil. Fertilization (Day 0) was accomplished by adding $20 \mu \mathrm{L}$ of the sperm pellet allowing the obtention of 5000 spermatozoa per drop. Gametes were coincubated for 18 to $20 \mathrm{~h}$ at $39^{\circ} \mathrm{C}$ in $5 \% \mathrm{CO}_{2}$ in air under high humidity.

Presumptive zygotes were vortexed for 2 min to separate cumulus cells, washed three times in HM and twice in the culture medium before putting them in the culture droplets. Culture medium consisted of modified synthetic oviductal fluid (mSOF) [28] containing $6 \mathrm{~g} / \mathrm{L}$ BSA. The mSOF was freshly prepared every week and adjusted to $285 \mathrm{mOsm}$ and $\mathrm{pH} 7.2$ to 7.3. Droplets of $50 \mu \mathrm{L} \mathrm{mSOF}$ were prepared in four-well dishes under mineral oil and equilibrated for $2 \mathrm{~h}$ before the addition of 35 to 40 zygotes per drop; culture was carried out at $39{ }^{\circ} \mathrm{C}, 5 \% \mathrm{CO}_{2}, 5 \%$ $\mathrm{O}_{2}$ and $90 \% \mathrm{~N}_{2}$. Medium was renewed on Days 3 and 6 post IVF.

In the experiment evaluating the effect of the culture media on the in vitro development of zygotes produced with both sorted and unsorted sperm, three different culture systems were tested: (1) Vero cells: $50 \mu \mathrm{L}$ B2 medium (CCB, Paris, France) supplemented with 5\% FCS, seeded with Vero cells and overlaid with mineral oil [29]; (2) mSOF-FCS: embryo culture in mSOF containing amino acids, citrate, and myoinositol [28], without protein up to Day 3, and supplemented with $10 \%$ FCS from Days 3 to 8 ; and (3) mSOF-BSA: embryo culture in mSOF + $6 \mathrm{~g} / \mathrm{L}$ BSA. Embryos in Vero cells were cultured at $39^{\circ} \mathrm{C}$ and $5 \% \mathrm{CO}_{2}$ in air. Twenty-five $\mu \mathrm{L}$ of medium were renewed with fresh medium every 2 days.

Cleavage (Day 3 post-IVF) and development (Days 6 to 8 post IVF) rates were recorded following reported criteria [30].

\subsection{Embryo vitrification}

Day 7 and 8 excellent and good expanded blastocysts were vitrified in fiber plugs (CVM) by using the vitrification solutions described by Vajta et al. [31]. Briefly, embryos were first handled in a basic vitrification medium (BV), consisting of TCM 199-HEPES + $20 \%$ FCS. All procedures were performed in a warm room $\left(30{ }^{\circ} \mathrm{C}\right)$ on a heated surface $\left(41{ }^{\circ} \mathrm{C}\right)$. Groups of one to eight blastocysts were exposed to $\mathrm{BV}$ with $7.5 \%$ ethylene-glycol (EG) $+7.5 \%$ DMSO (vitrification solution-1) for $3 \mathrm{~min}$ and then moved into a microdrop containing BV with $16.5 \% \mathrm{EG}+16.5 \% \mathrm{DMSO}+0.5 \mathrm{M}$ sucrose (vitrification solution-2; VS2). Blastocysts (one to eight) were then loaded into a micropipette in 0.3 to 2.5 $\mu \mathrm{L}$ of VS2 (one embryo per $0.3 \mu \mathrm{L}$ VS2), and put in a microdrop in the hook of the fiber plug. Then, the sample was vitrified by touching with the hook in a supercooled block placed in liquid nitrogen. The time spent by the embryos in VS2 (including loading) was 20 to $25 \mathrm{sec}$. Vitrified embryos were stored in closed straws up to warming, that was performed by immersing the end of the fiber plug directly in $1.2 \mathrm{~mL}$ of $0.25 \mathrm{M}$ sucrose in BV. Embryos were kept for $5 \mathrm{~min}$, and then transferred into $0.15 \mathrm{M}$ sucrose in BV for another $5 \mathrm{~min}$, and subsequently transferred and washed twice in BV.

\subsection{In vitro survival after warming}

After warming, blastocysts were rinsed twice in the culture medium and then cultured in droplets of $50 \mu \mathrm{L}$ of mSOF [28] containing $6 \mathrm{~g} / \mathrm{L}$ BSA and $10 \%$ FCS. Embryo survival was evaluated in terms of re-expansion and hatching at 24 and $48 \mathrm{~h}$.

\subsection{In vivo survival after transfer}

Fresh and vitrified/warmed Day 7 expanded embryos were transferred to synchronous mixed breed recipient heifers (one embryo per recipient).

\subsection{Embryo transfer}

Experiments were carried out from June 2010 to June 2011 within animals belonging to our experimental herd.

Candidate animals were cyclic heifers aged 15 to 18 mo, with $350 \mathrm{~kg}$ of required live weight $(50 \%$ to $60 \%$ of adult weight) and body condition score of $3 \pm 0.5$ units (scale of one to five, where one indicates emaciated and five obese). Health status was verified clinically by general and gynecologic examination. Estrus cycles were synchronized by using an intravaginal progestagen device (PRID ALPHA, Ceva, Barcelona, Spain) for 10 days combined with a prostaglandin analogue (Dynolitic, 
Pfizer, Madrid, Spain) injected 48 h before progestagen removal. Estrus detection (Day 0; 2.5 days after the $\mathrm{PGF}_{2 \alpha}$ administration on average) was based on a three times per day monitoring of behavioral signs and serum levels of progesterone (P4). Serum P4 was determined by ELISA by means of DRG EIA KIT (DRG International, Mountainside, NJ, USA). The test was sensitive starting from $0.5 \mathrm{ng} / \mathrm{mL}$, and cross-reactivity from steroids other than $\mathrm{P} 4$ was less than $1 \%$. Intra- and interassay coefficients of variation were $6 \%$ and $7 \%$, respectively.

Selection of recipients was performed immediately before embryo transfer (ET). Recipient acceptance focused on time elapsed from standing estrus (6.5 to 7.5 days), quality of corpus luteum (CL) and serum levels of P4 on Day 0 and Day 7, as previously reported in Hidalgo et al. [32]. Recipients with two negative pregnancy diagnoses were discarded for a third ET.

Embryos were nonsurgically transferred to the uterine horn ipsilateral to the CL, under epidural anesthesia ( $5 \mathrm{~mL}, 2 \%$ lidocaine chlorhydrate, Laboratorios Ovejero, Leon, Spain). Excellent quality fresh and vitrified/ warmed embryos were washed twice in embryo holding medium (Holding Embryo Transfer Medium, 019449; IMV, l'Aigle, France) and then loaded into straws in the same medium. Pregnancy diagnosis was evaluated by ultrasound on Day 40 and confirmed on Day 62 .

\subsection{Analysis of embryonic sex by PCR}

The efficiency of the sex-sorting sperm was inferred by determining the embryonic sex by a built-in control PCR technique using transferable stage embryos [33]. Briefly, fresh and vitrified/warmed blastocysts were incubated for $2 \mathrm{~min}$ in pronase $(5 \mathrm{mg} / \mathrm{mL}$ in PBS) to remove the zona pellucida. Then, embryos were washed four times in PBS $+0.1 \mathrm{mg} / \mathrm{mL}$ polyvinyl alcohol (PVA), individually collected in $0.3 \mu \mathrm{L}$ of medium into PCR $0.2 \mathrm{~mL}$ tube strips (Bio-Rad, Madrid, Spain) and stored at $-20{ }^{\circ} \mathrm{C}$ until analysis. Embryonic DNA was extracted by a heat shock at $95^{\circ} \mathrm{C}$ for $10 \mathrm{~min}$ in $6 \mu \mathrm{L}$ deionized water. Embryonic sex by PCR was analyzed with amelogenin primers. The bovine amelogenin cDNA sequences were obtained by GenBank accession no: NM_001014984 (AMELX) and NM_174240 (AMELY). The PCR reactions were carried out with a total volume of $20 \mu \mathrm{L}$ containing $6 \mu \mathrm{L}$ heated water. The reaction mixture was formed by $2 \times$ Qiagen Multiplex master mixes (containing Hot Star Taq DNA Polymerase, Multiplex PCR Buffer, dNTP mix), Q-solution 5x, 3.0 $\mu \mathrm{M}$ AMEL forward (5'-CAG CCA AAC CTC CCT CTG C) reverse (5'-CCC GCT TGG TCT TGT CTG TTG C). PCR rounds were performed in a Bio-Rad thermocycler with one cycle of $95{ }^{\circ} \mathrm{C}$ for $15 \mathrm{~min}, 35$ cycles of $94{ }^{\circ} \mathrm{C}$ for $20 \mathrm{sec}$, annealing temperatures of $60{ }^{\circ} \mathrm{C}$ for $40 \mathrm{sec}$, and $72{ }^{\circ} \mathrm{C}$ for $20 \mathrm{sec}$, and a final extension step of $72{ }^{\circ} \mathrm{C}$ for $10 \mathrm{~min}$. Products were visualized on a Syber Green stained $2 \%$ agarose gel. The gel was visualized under ultraviolet illumination, where single fragments of 270 base pair (bp) were assigned as female, and two fragments of $270 \mathrm{bp}$ and 214 bp were considered male (Fig. 1). Every PCR reaction was carried out with three controls: male (unsorted sperm) and female (ovarian tissue) genomic DNA, and a negative control with deionizer water.

\subsection{Experimental design}

\subsubsection{Experiment 1}

To analyze the effect of sorting procedure on embryo development, we compared the developmental

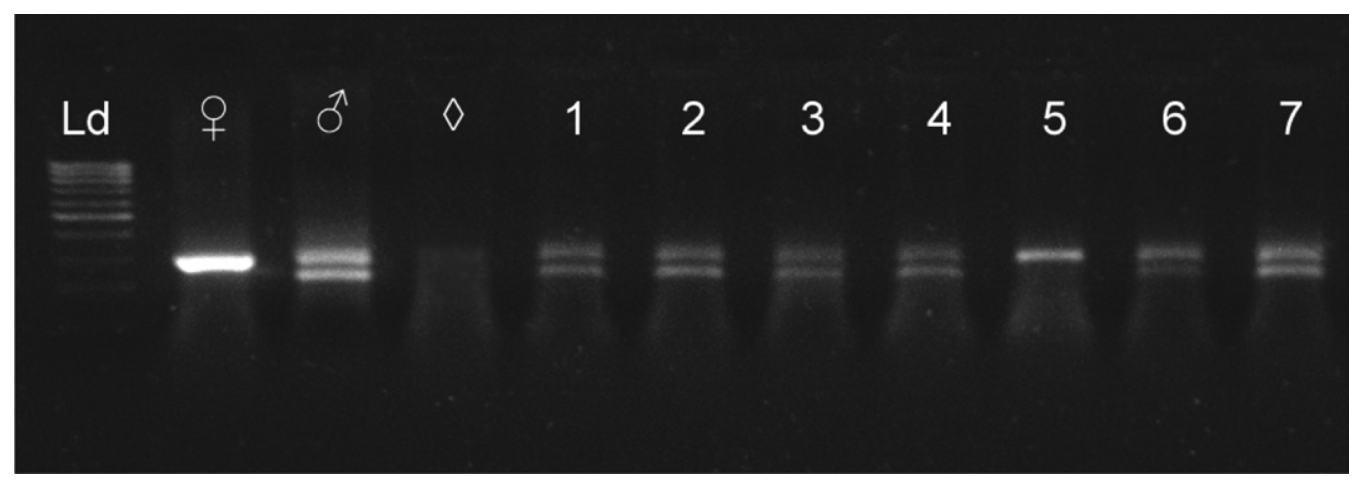

Fig. 1. Gel electrophoresis representative of polymerase chain reaction (PCR) sexing reactions. Samples were processed by amelogenin (aMEL), which shows a 270 base pair (bp) band for females and two bands (270 bp and 214 bp) for males. From left to right: Ladder (Ld-100 bp); female control ( + ); male control ( $₫)$; blank $(\diamond)$; embryo 1 (male); embryo 2 (male); embryo 3 (male); embryo 4 (male); embryo 5 (female); embryo 6 (male); embryo 7 (male). 
rates of zygotes fertilized with sorted and unsorted sperm from five bulls. For this, presumptive zygotes were cultured in $\mathrm{mSOF}+6 \mathrm{~g} / \mathrm{L}$ BSA up to Day 8 .

Subsequently, we analyzed the effect of the culture system in the development of bovine embryos produced after IVF with sexed sperm, and we recorded the development of embryos produced with female and male sperm from two out of the five bulls used in the above described experiment. Embryos were cultured in the three culture media described in the IVF and culture section.

\subsubsection{Experiment 2}

We analyzed the quality of embryos produced with sexed sperm in terms of ability to develop in vitro after vitrification/warming. Day 7 (168 h post-IVF) and Day 8 (192 h post-IVF) excellent quality vitrified/warmed blastocysts were cultured in $\mathrm{mSOF}+6 \mathrm{~g} / \mathrm{L} \mathrm{BSA}$ and $10 \%$ FCS for $48 \mathrm{~h}$ to evaluate re-expansion and hatching rates.

\subsubsection{Experiment 3}

In this experiment the quality of embryos produced with sexed sperm was measured as the ability to establish a pregnancy, after the transfer of fresh and vitrified/ warmed embryos.

Day 7 expanded blastocysts were transferred fresh or after vitrification and warming to synchronous recipients. Before ET, warmed blastocysts were allowed to re-expand for $2 \mathrm{~h}$ in $\mathrm{mSOF}+6 \mathrm{~g} / \mathrm{L} \mathrm{BSA}+10 \%$ FCS. As no differences were obtained within in vitro survival rates after vitrification/warming between the three culture systems (unpublished data, not shown) we selected the simple medium mSOF $+6 \mathrm{~g} / \mathrm{L}$ BSA to produce embryos for transfer to recipients.

\subsubsection{Experiment 4}

To evaluate the efficiency of sexed semen separation, blastocysts produced with sorted semen (male and female) were collected on Day 8 and processed by PCR to either confirm or discard the expected embryo sex.

\subsection{Statistical analysis}

The proportion of oocytes that cleaved and developed to the below described stages were calculated for each replicate. Treatment effects were analyzed by least-square analysis of variance using the General Linear Models procedure of SAS [34]. The model included the main effects of replicate, culture treatment, sperm sex, sorted/unsorted sperm, age of the embryo (Day 7 and Day 8), and bull used. This procedure performs the analysis of variance for unbalanced data. General Linear Model was used to estimate the least square means for each fixed effect having a significant $F$ value. Duncan's multiple-range test was used to compare raw means calculated for the main effects. All values reported are least square means \pm SEM. Because of the discrete definition of pregnancy rates and calving rates, before performing a statistical analysis using a linear model, as described above, the statistical significance of the embryonic sex (expected and diagnosed) and the treatment (fresh or vitrified/warmed) was explored using Proc CATMOD of SAS/STAT (SAS for Windows, Version 9.0, Cary, NC, USA).

\section{Results}

\subsection{Experiment 1}

In this experiment, a total of 6662 oocytes were processed. Table 1 shows the bull $(\mathrm{N}=5)$ effects on embryo development rates. Within the five bulls used, we found a significant decrease in development rates of embryos produced with sorted sperm, as compared with embryos fertilized with unsorted sperm. Moreover, bull

Table 1

In vitro development of bovine embryos fertilized with either conventional, unsorted, or sex-sorted sperm from five bulls and cultured in modified synthetic oviductal fluid $+6 \mathrm{~g} / \mathrm{L}$ BSA.

\begin{tabular}{|c|c|c|c|c|c|c|c|c|}
\hline & \multirow[t]{3}{*}{$\mathrm{N}$} & \multirow[t]{3}{*}{$\mathrm{R}$} & \multicolumn{2}{|c|}{ Day 3} & \multicolumn{2}{|c|}{ Day 6} & \multicolumn{2}{|c|}{ Day 8} \\
\hline & & & \multicolumn{2}{|c|}{$\%>5$ Cells } & \multicolumn{2}{|c|}{$\%>$ Morulae } & \multicolumn{2}{|c|}{$\%$ Blastocysts } \\
\hline & & & Unsorted & Sorted & Unsorted & Sorted & Unsorted & Sorted \\
\hline Bull 1 & 776 & 33 & $40.3 \pm 5.9^{\mathrm{a}, \mathrm{x}}$ & $26.3 \pm 5.5^{\mathrm{b}, \mathrm{x}}$ & $20.3 \pm 4.5^{\mathrm{a}, \mathrm{x}}$ & $10.2 \pm 4.3^{\mathrm{b}, \mathrm{x}}$ & $17.1 \pm 3.5^{\mathrm{a}, \mathrm{x}}$ & $8.6 \pm 3.3^{b}$ \\
\hline Bull 2 & 1443 & 22 & $27.6 \pm 3.5^{\mathrm{a}, \mathrm{x}}$ & $19.1 \pm 3.1^{\mathrm{b}, \mathrm{x}}$ & $15.1 \pm 2.7^{\mathrm{a}, \mathrm{x}}$ & $8.9 \pm 2.4^{\mathrm{b}, \mathrm{x}}$ & $8.6 \pm 2.1^{\mathrm{a}, \mathrm{y}}$ & $4.9 \pm 1.9^{b}$ \\
\hline Bull 3 & 1869 & 42 & $26.9 \pm 5.5^{\mathrm{a}, \mathrm{x}}$ & $19.6 \pm 5.2^{\mathrm{b}, \mathrm{x}}$ & $37.2 \pm 4.2^{\mathrm{a}, \mathrm{y}}$ & $26.8 \pm 4.0^{\mathrm{b}, \mathrm{y}}$ & $18.2 \pm 3.3^{\mathrm{a}, \mathrm{x}}$ & $10.0 \pm 3.1^{b}$ \\
\hline Bull 4 & 658 & 18 & $16.7 \pm 6.2^{\mathrm{a}, \mathrm{y}}$ & $9.6 \pm 5.5^{\mathrm{b}, \mathrm{y}}$ & $29.6 \pm 4.8^{\mathrm{a}, \mathrm{y}}$ & $21.1 \pm 4.3^{\mathrm{b}, \mathrm{x}, \mathrm{y}}$ & $16.5 \pm 3.7^{\mathrm{a}, \mathrm{x}}$ & $8.5 \pm 3.3^{b}$ \\
\hline Bull 5 & 1916 & 33 & $14.8 \pm 3.7^{\mathrm{a}, \mathrm{y}}$ & $5.6 \pm 3.6^{\mathrm{b}, \mathrm{y}}$ & $6.4 \pm 2.9^{\mathrm{z}}$ & 0 & $6.2 \pm 2.2^{\mathrm{y}}$ & 0 \\
\hline
\end{tabular}

$\mathrm{N}$, number of zygotes cultured; R, replicates (includes the total of replicates for IVF with unsorted and sorted sperm. Superscript letters a and $\mathrm{b}$ in the same row, for the same bull and developmental stage, differ statistically $(\mathrm{P}<0.05)$; Superscript letters $\mathrm{x}$, $\mathrm{y}$, and $\mathrm{z}$ in the same column (among bulls) differ significantly $(\mathrm{P}<0.05)$. 
Table 2

In vitro development of bovine embryos fertilized with either untreated or sorted sperm and cultured in Vero cells + B2 medium, modified synthetic oviductal fluid $(\mathrm{mSOF})+10 \%$ fetal calf serum $(\mathrm{FCS})$ or $\mathrm{mSOF}+6 \mathrm{~g} / \mathrm{L} \mathrm{BSA}$.

\begin{tabular}{lccccccc}
\hline Treatment & & & & Day 3, $>5$ cells & Day 6, $>$ morulae & Day 7, blastocysts & Day 8, blastocysts \\
\cline { 1 - 4 } Culture & Sorted & $\mathrm{N}$ & $\mathrm{R}$ & & & & \\
\hline Vero cells & No & 226 & 7 & $65.0 \pm 5.5^{\mathrm{x}}$ & $46.4 \pm 3.6^{\mathrm{x}}$ & $34.3 \pm 2.6^{\mathrm{x}}$ & $38.6 \pm 2.8^{\mathrm{x}}$ \\
mSOF + FCS & No & 233 & 7 & $63.7 \pm 5.5^{\mathrm{x}}$ & $47.2 \pm 3.6^{\mathrm{x}}$ & $34.2 \pm 2.6^{\mathrm{x}}$ & $38.3 \pm 2.8^{\mathrm{x}}$ \\
mSOF + BSA & No & 378 & 11 & $51.1 \pm 4.2^{\mathrm{x}}$ & $34.2 \pm 2.8^{\mathrm{x}}$ & $18.8 \pm 2.0^{\mathrm{y}}$ & $22.5 \pm 2.1^{\mathrm{y}}$ \\
Vero cells & Yes & 503 & 14 & $25.8 \pm 4.0^{\mathrm{y}}$ & $21.8 \pm 2.7^{\mathrm{y}}$ & $11.8 \pm 1.9^{\mathrm{y}, \mathrm{z}}$ & $12.9 \pm 2.1^{\mathrm{z}}$ \\
mSOF + FCS & Yes & 480 & 13 & $27.3 \pm 4.2^{\mathrm{y}}$ & $20.9 \pm 2.8^{\mathrm{y}}$ & $11.7 \pm 1.0^{\mathrm{y}, \mathrm{z}}$ & $14.3 \pm 1.6^{\mathrm{y}, \mathrm{z}}$ \\
mSOF + BSA & Yes & 773 & 21 & $23.9 \pm 3.2^{\mathrm{y}}$ & $16.5 \pm 2.1^{\mathrm{y}}$ & $7.5 \pm 1.7^{\mathrm{z}}$ & $10.0 \pm 1.6^{\mathrm{z}}$ \\
\hline
\end{tabular}

Data are percentages of development related to the zygotes cultured, and are expressed as least square means \pm standard error. Different superscript letters in the same column differ statistically, $\mathrm{P}<0.05$.

$\mathrm{N}$, oocytes; R, replicates.

effects were observed both with sorted and unsorted sperm. The development of zygotes obtained after IVF with unsorted and sorted sperm, and subsequently cultured in three different culture systems was shown in Table 2. Sexed sperm showed significantly reduced development rates as compared with unsorted sperm. Thus, sorted sperm showed reduced five- to eight-cell, Day 6 morulae, and Day 7 and 8 blastocyst rates over unsorted sperm within the three culture systems analyzed.

Day 7 and 8 blastocyst rates produced with unsorted sperm after culture in Vero cells or mSOF + FCS were significantly higher than those obtained after culture in $\mathrm{mSOF}+\mathrm{BSA}$. Table 3 shows development of zygotes obtained after IVF with unsorted and sorted female and male sperm. No differences in developmental rates were found between zygotes produced with male or female ejaculates.

\subsection{Experiment 2}

In vitro survival and hatching rates after vitrification/warming are presented in Table 4. Day 7 embryos survived at higher rates than Day 8 embryos (data not shown), No differences were obtained in survival and hatching rates of vitrified/warmed embryos produced with untreated or sorted sperm. Male and female embryos had similar re-expansion and hatching rates.

\subsection{Experiment 3}

No significant differences were found in pregnancy rates after transfer of fresh or vitrified/blastocysts (Table 5). Male and female embryos produced similar pregnancy rates.

\subsection{Experiment 4}

Table 6 shows sex accuracy of the sorting procedure as diagnosed by PCR of blastocysts produced with male or female sorted sperm. Embryos produced with Xsorted or Y-sorted sperm did not differ in their expected sex rates as confirmed by PCR.

\section{Discussion}

In this study we have examined the blastocyst development and quality rates of oocytes fertilized in vitro with sex-sorted sperm. We have confirmed an individual effect of the bull, and a capacity of the zygotes produced with sorted sperm to develop at lower rates than embryos produced with unsorted sperm. The ability of the culture system to influence the embryo development was not capable to recover the reduced developmental capacity of embryos produced with sexed sperm. However, the cryoresistance to vitrification of these embryos did not differ from that of con-

Table 3

In vitro development of bovine embryos fertilized with untreated, male-sorted, and female-sorted spermatozoa.

\begin{tabular}{lcccccc}
\hline Ejaculate & $\mathrm{N}$ & $\mathrm{R}$ & Day 3, $>5$ cells & Day 6,> morulae & Day 7, blastocysts & Day 8, blastocysts \\
\hline Unsorted & 837 & 25 & $59.0 \pm 3.5^{\mathrm{x}}$ & $42.8 \pm 2.3^{\mathrm{x}}$ & $29.3 \pm 1.7^{\mathrm{x}}$ & $33.2 \pm 1.9^{\mathrm{x}}$ \\
Female & 827 & 24 & $27.4 \pm 3.5^{\mathrm{y}}$ & $21.9 \pm 2.4^{\mathrm{y}}$ & $11.9 \pm 1.8^{\mathrm{y}}$ & $13.6 \pm 1.9^{\mathrm{y}}$ \\
Male & 929 & 24 & $24.3 \pm 3.6^{\mathrm{y}}$ & $19.6 \pm 2.4^{\mathrm{y}}$ & $11.4 \pm 1.8^{\mathrm{y}}$ & $14.0 \pm 2.0^{\mathrm{y}}$ \\
\hline
\end{tabular}

Data are percentages of development related to the zygotes cultured, and are expressed as least square means \pm standard error. Different superscript letters in the same column, differ statistically, $\mathrm{P}<0.001$.

$\mathrm{N}$, oocytes; R, replicates. 
Table 4

In vitro survival of vitrified/warmed blastocysts produced after IVF with sexed (male, female) or conventional unsorted sperm, and cultured in modified synthetic oviductal fluid $+6 \mathrm{~g} / \mathrm{L}$ BSA $+10 \%$ fetal calf serum.

\begin{tabular}{|c|c|c|c|c|c|}
\hline \multirow[t]{2}{*}{ Sperm } & \multirow[t]{2}{*}{$\mathrm{N}$} & \multicolumn{2}{|c|}{24 h $(\%)$} & \multicolumn{2}{|c|}{48 h $(\%)$} \\
\hline & & Re-expanded & Hatched & Re-expanded & Hatched \\
\hline Unsorted & 90 & $73.8 \pm 14.4$ & $51.5 \pm 10.9$ & $63.3 \pm 15.1$ & $63.4 \pm 12.7$ \\
\hline Female & 106 & $62.3 \pm 13.8$ & $41.3 \pm 10.5$ & $53.5 \pm 14.5$ & $47.0 \pm 12.2$ \\
\hline Male & 110 & $79.4 \pm 13.1$ & $49.9 \pm 9.9$ & $71.4 \pm 13.7$ & $54.8 \pm 11.6$ \\
\hline
\end{tabular}

Data are percentages of development related to the embryos warmed, and are expressed as least square means \pm standard error; blastocysts were vitrified in 15 replicates and warmed in three replicates. No significant differences were found. Significant effect: blastocyst age (Day 7 vs. Day 8).

ventionally produced embryos. Moreover, our data indicate that male and female embryos produced with sorted sperm have the same quality, and can be effectively vitrified.

Although probably affected by the number of transfers, the most important quality criterion, the pregnancy rate after embryo transfer, did not differ between fresh and vitrified/warmed blastocysts.

The production of sex-known calves has been a goal for researchers for years. Factors that have been reported to influence sex ratio in cattle are the timing of insemination in vivo [35], the maturation stage of the oocyte at the time of in vitro fertilization [15], modifications of the fertilization procedure $[20,36]$, and the postfertilization culture conditions [37].

At present, the fastest, most reliable, and potentially most cost-effective procedure for sperm sexing is flow cytometry [38-40], being the only routine procedure for sexing cattle sperm currently available for practical applications $[41,42]$. However, consistent with our results, sexed sperm shows diminished efficacy in vitro as well as in vivo, because of detrimental effects exerted by the sorting procedure on sperm cells [43]. Alterations observed in sorted sperm consist of impairment of the motility, enhanced membrane and acrosomal damage [44], reduced lifespan [45], an acceleration of the acrosome reaction [46], and increased rates of capacitated spermatozoa [47]. Collectively, together with the usually reduced number of spermatozoa per straw, these factors may explain the negative impact in fertility when sorted sperm is used both for AI and multiovulation and embryo transfer programs. According to a recent review, fertility rates for sex-sorted sperm are now usually in the range of $70 \%$ to $80 \%$ of unsexed sperm at normal doses in well-managed herds. The predicted average pregnancy rate for sex-sorted sperm by $\mathrm{AI}$ in the dairy industry is approximately $51 \%$, and it can be considerably lower $[10,11]$.

High variability in development of IVP bovine embryos with sexed sperm has been reported in several studies [48]. Previous investigations have shown that, at least, a part of these variations may be because of different capacities of bulls to produce embryos and a high male effect on the efficiency of an IVF program [49]. Fertilization rates were $10 \%$ to $20 \%$ lower with regard to IVP using nonsorted sperm [3]. This evidence has been confirmed in our study, in which a reduction within cleavage and development rates has been observed in all tested bulls, even when different culture systems have been assayed. The individual effect of the sire we observed agrees with other authors [24,50] and makes it difficult to establish comparisons between

Table 5

Pregnancy rates, sex diagnosis, and calves born alter the transfer of both fresh and vitrified/warmed expanded blastocysts produced with sexed sperm.

\begin{tabular}{|c|c|c|c|c|c|c|}
\hline \multirow{2}{*}{$\begin{array}{l}\text { Embryo transfer } \\
\text { Cumulative }\end{array}$} & \multirow[t]{2}{*}{$\mathrm{N}$} & \multirow[t]{2}{*}{ P D62 } & \multicolumn{2}{|c|}{ Pregnancy rate } & \multirow[t]{2}{*}{ Calves born* } & \multirow[t]{2}{*}{ Expected sex at birth } \\
\hline & & & Day 40 & Day 62 & & \\
\hline Male & 18 & 9 & $49.1 \pm 12.5$ & $49.1 \pm 12.5$ & 8 & $5 / 8$ \\
\hline Female & 35 & 17 & $45.8 \pm 8.9$ & $45.8 \pm 8.9$ & 13 & $13 / 13$ \\
\hline Fresh & 27 & 15 & $52.8 \pm 11.4$ & $52.8 \pm 11.4$ & 12 & \\
\hline Vitrified & 26 & 11 & $42.0 \pm 10.1$ & $42.0 \pm 10.1$ & 9 & \\
\hline
\end{tabular}

Pregnancy rates are expressed as least square means \pm standard error.

$\mathrm{N}$, number of transfers; P D62, number of pregnancies on Day 62.

* One female calf was delivered 15 days before the expected date; one female calf was born dead. Two pregnancies are still ongoing (one from fresh and one from vitrified/warmed female embryos). 
Table 6

Sex diagnosis by polymerase chain reaction (PCR) of Day 8 blastocysts produced with sexed semen.

\begin{tabular}{lccc}
\hline Sexed semen & N1 & N2 & Accuracy (\%) \\
\hline Female & 90 & 87 & 96.6 \\
Male & 86 & 84 & 97.7 \\
\hline
\end{tabular}

No differences were found.

N1, embryos processed for PCR; N2, embryos with the expected sex.

experiments. However, decreased [2,3,14,51,52] or comparable $[15,27,53]$ fertilization rates have been reported when using sorted sperm in comparison with unsorted sperm. Otherwise, Lu and Seidel [4] postulated that, when the adequate heparin and PHE concentrations have been established, there should be no differences between sexed and untreated sperm.

The embryo culture period is determinant for the quality of the embryo [54-56], influencing, among other traits, cell numbers and distribution, cryoresistance, and the ability to establish a pregnancy. In this work, we have tested three culture systems with the aim of improving the developmental ability of the embryos fertilized with sorted sperm.

The supplementation of the culture medium with FCS or Vero cells (also containing FCS) increased development rates of nonsexed embryos. However, within embryos produced with sexed spermatozoa, such an increase was nonsignificant. It is known that the addition of serum to culture media has a biphasic effect on embryo development, inhibiting the early stages and promoting the development of morulae and blastocysts [57,58]. On the other hand, the use of Vero cells shows an embryotrophic effect by producing growth factors and also removing toxicants or inhibitory substances derived from the embryo [59]. However, in a previous work [33] we demonstrated that embryos produced without serum had better survival and hatching rates after vitrification (open pulled straw), pointing toward different qualities among the embryos. To our knowledge, there are no data about how culture systems might improve the diminished developmental ability of embryos produced with sexed sperm, and we hypothesize that in our case the developmental ability of the embryos fertilized with sexed sperm does not depend on the culture system, but on the bull and the damage inflicted to the sperm by the sorting process.

It has been reported that IVF of oocytes with sexed sperm led to embryos with slower developmental kinetics, and blastocysts with ultrastructural alterations affecting numbers and structure of mitochondria, rough endoplasmic reticulum, and nuclear membrane [19]. Also, Morton et al. [60] describe a reduced expression of developmentally important genes in embryos produced with sexed sperm.

The resistance of the embryo to cryopreservation is one of the most useful parameters allowing an evaluation of the embryo quality [61]. A reliable embryo production system should be coupled with a cryopreservation protocol leading to improved survival rates after thawing/warming both in vitro and in vivo (i.e., pregnancies). Such a step will greatly contribute to improve reproductive biotechnologies.

We have analyzed the in vitro survival of the embryos produced with sorted or unsorted sperm after vitrification in fiber plugs. We did not obtain differences within in vitro survival of embryos produced with sexed sperm, when compared with the respective controls. In fact, survival and hatching rates are similar to those recently obtained in a previous experiment in which nonsexed embryos were cultured in the same conditions and vitrified/warmed as we have done in this work (unpublished). These data indicate that the quality of the embryos produced with sexed sperm is similar to that of controls in terms of cryoresistance. Moreover, no differences were detected between embryos produced with $\mathrm{X}$ - or Y-bearing spermatozoa (data not shown). Xu et al. [24] reported $90 \%$ in vitro survival rate with embryos produced with sorted and nonsorted sperm, although the culture medium used by these authors differed from that used in the present work.

The best method to analyze the quality of an embryo is its ability to establish a pregnancy and produce an offspring. In our work, we have transferred 27 and 26 fresh and vitrified/warmed expanded blastocysts, respectively, that yielded comparable pregnancy rates (Day 62), with no differences between female and male embryos. These results should be carefully interpreted, as ET numbers cannot ensure fully conclusive data. However, our pregnancy rates are higher than those reported by other authors [24,27,62,63].

From sexing of blastocysts a similar accuracy for separation of X-and Y-bearing sperm can be inferred. Our sexing method [33] consists of an accurate built-in control PCR, which is particularly appropriate when an accurate embryonic sex diagnosis is necessary [64]. Commercially available, sex-sorted sperm usually allow embryos of the desired sex at rates of $90 \%$ or higher, which has been confirmed by PCR in the present work.

A recent report in porcine [65] describes the birth of piglets after transfer of in vivo-produced porcine em- 
bryos with the use of the CVM method. Vitrification of embryos by the CVM system in fiber plugs is herein described as an optimal technology for cryopreservation of IVP blastocysts. In our hands, this procedure allowed us to obtain the first sexed calves born after the transfer of IVP vitrified/warmed embryos, with pregnancy rates (at 62 days) of $42 \%$. These results demonstrate that vitrification is a useful tool to cryopreserve sexed IVF embryos allowing good pregnancy rates that are, in our conditions, comparable with those obtained with fresh embryos.

\section{Acknowledgments}

This work was funded by RTA2008-0082. M. Muñoz, and B. Trigal are sponsored by RYC08-03454 and Cajastur. Gemini, COST Action FA0702.

\section{Competing interests}

J. Moreno is employed by Sexing Technologies. The remaining authors declare no conflicts of interest.

\section{References}

[1] Hossein-Zadeh NG, Nejati-Javaremi A, Miraei-Ashtiani SR, Kohram H. Bio-economic evaluation of the use of sexed semen at different conception rates and herd sizes in Holstein populations. Anim Reprod Sci 2010;121:17-23.

[2] Presicce GA, Xu J, Gong G, Moreno JF, Chaubal S, Xue F, et al. Oocyte source and hormonal stimulation for in vitro fertilization using sexed spermatozoa in cattle. Vet Med Int 2010; 2011.pii:145626.

[3] Seidel GE Jr. Overview of sexing sperm. Theriogenology 2007; 68:443-6.

[4] Lu KH, Seidel GE Jr. Effects of heparin and sperm concentration on cleavage and blastocyst development rates of bovine oocytes inseminated with flow cytometrically-sorted sperm. Theriogenology 2004;62:819-30.

[5] Suh TK, Schenk JL, Seidel GE Jr. High pressure flow cytometric sorting damages sperm. Theriogenology 2005;64:1035-48.

[6] Puglisi R, Vanni R, Galli A, Balduzzi D, Parati K, Bongioni G, et al. In vitro fertilisation with frozen-thawed bovine sperm sexed by flow cytometry and validated for accuracy by real-time PCR. Reproduction 2006;132:519-26.

[7] Totey SM, Pawshe CH, Singh GP. Effects of bull and heparin and sperm concentrations on in vitro fertilization of buffalo (Bubalus bubalis) oocytes matured in vitro. Theriogenology 1993;39:887-98.

[8] Hu JH, Jiang ZL, Lv RK, Li QW, Zhang SS, Zan LS, et al. The advantages of low-density lipoproteins in the cryopreservation of bull semen. Cryobiology 2011;62:83-7.

[9] Bodmer M, Hässig M, Janett F, den Daas N, Reichert P, Thun R. Fertility in heifers and cows after low dose insemination with sex-sorted and non-sorted sperm under field conditions. Theriogenology 2005;64:1647-55.
[10] Grant VJ, Chamley LW. Sex-sorted sperm and fertility: an alternative view. Biol Reprod 2007;76:184-8.

[11] Schenk JL, Cran DG, Everett RW, Seidel GE Jr. Pregnancy rates in heifers and cows with cryopreserved sexed sperm: effects of sperm numbers per inseminate, sorting pressure and sperm storage before sorting. Theriogenology 2009;71:717-28.

[12] Sá Filho MF, Ayres H, Ferreira RM, Nichi M, Fosado M, Campos Filho EP, et al. Strategies to improve pregnancy per insemination using sex-sorted semen in dairy heifers detected in estrus. Theriogenology 2010;74:1636-42.

[13] Soares JG, Martins CM, Carvalho NA, Nicacio AC, AbreuSilva AL, Campos Filho EP, et al. Timing of insemination using sex-sorted sperm in embryo production with Bos indicus and Bos taurus superovulated donors. Anim Reprod Sci 2011;127: 148-53.

[14] Lu KH, Cran DG, Seidel GE Jr. In vitro fertilization with flowcytometrically-sorted bovine sperm. Theriogenology 1999;52: 1393-405.

[15] Bermejo-Alvarez P, Rizos D, Rath D, Lonergan P, Gutiérrez-Adán A. Can bovine in vitro-matured oocytes selectively process $\mathrm{X}$ - or Y-sorted sperm differentially? Biol Reprod 2008;79:594-7.

[16] Xu J, Chaubal SA, Du F. Optimizing IVF with sexed sperm in cattle. Theriogenology 2009;71:39-47.

[17] Frijters AC, Mullaart E, Roelofs RM, van Hoorne RP, Moreno $\mathrm{JF}$, Moreno O, et al. What affects fertility of sexed bull semen more, low sperm dosage or the sorting process? Theriogenology 2009;71:64-7.

[18] Zhang M, Lu KH, Seidel GE. Development of bovine embryos after in vitro fertilization of oocytes with flow cytometrically sorted, stained and unsorted sperm from different bulls. Theriogenology 2003;60:1657-63.

[19] Palma GA, Olivier NS, Neumüller Ch, Sinowatz F. Effects of sex-sorted spermatozoa on the efficiency of in vitro fertilization and ultrastructure of in vitro produced bovine blastocysts. Anat Histol Embryol 2008;37:67-73.

[20] Machado GM, Carvalho JO, Filho ES, Caixeta ES, Franco MM, Rumpf R, et al. Effect of Percoll volume, duration and force of centrifugation, on in vitro production and sex ratio of bovine embryos. Theriogenology 2009;71:1289-97.

[21] Rath D, Moench-Tegeder G, Taylor U, Johnson, LA. Improved quality of sex-sorted sperm: a prerequisite for wider commercial application. Theriogenology 2009;71:22-9.

[22] Wheeler MB, Rutledge JJ, Fischer-Brown A, VanEtten T, Malusky S, Beebe DJ. Application of sexed semen technology to in vitro embryo production in cattle. Theriogenology 2006;65:219-27.

[23] Yang X, Jiang S, Foote RH. Bovine oocyte development following different oocyte maturation and sperm capacitation procedures. Mol Reprod Dev 1993;34:94-100.

[24] Xu J, Guo Z, Su L, Nedambale TL, Zhang J, Schenk J, et al. Developmental potential of vitrified holstein cattle embryos fertilized in vitro with sex-sorted sperm. J Dairy Sci 2006;89:2510-8.

[25] Nadir S, Saacke RG, Bame J, Mullins J, Degelos S. Effect of freezing semen and dosage of sperm on number of accessory sperm, fertility, and embryo quality in artificially inseminated cattle. J Anim Sci 1993;71:199-204.

[26] Seidel GE Jr. Sexing mammalian spermatozoa and embryosstate of the art. J Reprod Fertil Suppl 1999;54:477-87.

[27] Liang XW, Lu YQ, Chen MT, Zhang XF, Lu SS, Zhang M, et al. In vitro embryo production in buffalo (Bubalus bubalis) using sexed sperm and oocytes from ovum pick up. Theriogenology 2008;69:822-6. 
[28] Holm P, Booth PJ, Schmidt MH, Greve T, Callesen H. High bovine blastocyst development in a static in vitro production system using SOFaa medium supplemented with sodium citrate and myo-inositol with or without serum-proteins. Theriogenology 1999;52:683-700.

[29] Gómez E, Rodríguez A, Muñoz M, Caamaño JN, Hidalgo CO, Morán E, et al. Serum free embryo culture medium improves in vitro survival of bovine blastocysts to vitrification. Theriogenology 2008;69:1013-21.

[30] Lindner GM, Wright RW Jr. Bovine embryo morphology and evaluation. Theriogenology 1983;20:407-16.

[31] Vajta G, Holm P, Kuwayama M, Booth PJ, Jacobsen H, Greve $\mathrm{T}$, et al. Open pulled straw (OPS) vitrification: a new way to reduce cryoinjuries of bovine ova and embryos. Mol Reprod Dev 1998;51:53-8.

[32] Hidalgo CO, Gómez E, Prieto L, Duque P, Goyache F, Fernández L, et al. Pregnancy rates and metabolic profiles in cattle treated with propylene glycol prior to embryo transfer. Theriogenology 2004;62:664-76.

[33] Trigal B, Gómez E, Díez C, Caamaño JN, Muñoz M, Moreno $\mathrm{JF}$, et al. Comparative study of PCR-sexing procedures using bovine embryos fertilized with sex-sorted spermatozoa. Spanish J Agric Res 2012;10:353-9.

[34] SAS Institute. SAS Version 8.2. SAS Institute, Inc., Cary, NC.

[35] Martinez F, Kaabi M, Martinez-Pastor F, Alvarez M, Anel E, Boixo JC, et al. Effect of the interval between estrus onset and artificial insemination on sex ratio and fertility in cattle: a field study. Theriogenology 2004;62:1264-70.

[36] Iwata $\mathrm{H}$, Shiono $\mathrm{H}$, Kon Y, Matsubara K, Kimura K, Kuwayama $\mathrm{T}$, et al. Effects of modification of in vitro fertilization techniques on the sex ratio of the resultant bovine embryos. Anim Reprod Sci 2008; 105:234-44.

[37] Gutiérrez-Adán A, Lonergan P, Rizos D, Ward FA, Boland MP, Pintado B, et al. Effect of the in vitro culture system on the kinetics of blastocyst development and sex ratio of bovine embryos. Theriogenology 2001;55:1117-26.

[38] Garner DL, Gledhill BL, Pinkel D, Lake S, Stephenson D, Van Dilla MA, et al. Quantification of the X- and Y-chromosomebearing spermatozoa of domestic animals by flow cytometry. Biol Reprod 1983;28:312-21.

[39] Seidel GE Jr., Garner DL. Current status of sexing mammalian spermatozoa. Reproduction 2002;124:733-43.

[40] Welch GR, Johnson LA. Sex preselection: laboratory validation of the sperm sex ratio of flow sorted X- and Y-sperm by sort reanalysis for DNA. Theriogenology 1999;52:1343-52.

[41] Maxwell WM, Evans G, Hollinshead FK, Bathgate R, De Graaf $\mathrm{SP}$, Eriksson BM, et al. Integration of sperm sexing technology into the ART toolbox. Anim Reprod Sci 2004;82-3:79-95.

[42] Cerchiaro I, Cassandro M, Dal Zotto R, Carnier P, Gallo L. A field study on fertility and purity of sex-sorted cattle sperm. J Dairy Sci 2007;90:2538-42.

[43] Garner DL, Seidel GE Jr. History of commercializing sexed semen for cattle. Theriogenology 2008;69:886-95.

[44] Carvalho JO, Sartori R, Machado GM, Mourão GB, Dode MA. Quality assessment of bovine cryopreserved sperm after sexing by flow cytometry and their use in in vitro embryo production. Theriogenology 2010;74:1521-30.

[45] Hollinshead FK, Gillan L, O’Brien JK, Evans G, Maxwell WM. In vitro and in vivo assessment of functional capacity of flow cytometrically sorted ram spermatozoa after freezing and thawing. Reprod Fertil Dev 2003;15:351-9.
[46] Mocé E, Graham JK, Schenk JL. Effect of sex-sorting on the ability of fresh and cryopreserved bull sperm to undergo an acrosome reaction. Theriogenology 2006;66:929-36.

[47] Maxwell WM, Long CR, Johnson LA, Dobrinsky JR, Welch GR. The relationship between membrane status and fertility of boar spermatozoa after flow cytometric sorting in the presence or absence of seminal plasma. Reprod Fertil Dev 1998;10:433-40.

[48] Galli C, Vassiliev I, Lagutina I, Galli A, Lazzari G. Bovine embryo development following ICSI: effect of activation, sperm capacitation and pre-treatment with dithiothreitol. Theriogenology 2003;60:1467-80.

[49] Palma GA, Sinowatz F. Male and female effects on the in vitro production of bovine embryos. Anat Histol Embryol 2004;33: 257-62.

[50] Bermejo-Alvarez P, Lonergan P, Rath D, Gutiérrez-Adan A, Rizos D. Developmental kinetics and gene expression in male and female bovine embryos produced in vitro with sex-sorted spermatozoa. Reprod Fertil Dev 2010;22:426-36.

[51] Cran DG, Johnson LA, Miller NG, Cochrane D, Polge C. Production of bovine calves following separation of $\mathrm{X}$ - and Y-chromosome bearing sperm and in vitro fertilisation. Vet Rec 1993;132:40-1.

[52] Cran DG, Johnson LA, Polge C. Sex preselection in cattle: a field trial. Vet Rec 1995;136:495-6.

[53] Underwood SL, Bathgate R, Pereira DC, Castro A, Thomson PC, Maxwell WM, et al. Embryo production after in vitro fertilization with frozen-thawed, sex-sorted, re-frozen-thawed bull sperm. Theriogenology 2010;73:97-102.

[54] Rizos D, Gutiérrez-Adán A, Pérez-Garnelo S, De La Fuente J, Boland MP, Lonergan P. Bovine embryo culture in the presence or absence of serum: implications for blastocyst development, cryotolerance, and messenger RNA expression. Biol Reprod 2003;68:236-43.

[55] Enright BP, Lonergan P, Dinnyes A, Fair T, Ward FA, Yang X, et al. Culture of in vitro produced bovine zygotes in vitro vs in vivo: implications for early embryo development and quality. Theriogenology 2000;54:659-73.

[56] Lonergan P, Pedersen HG, Rizos D, Greve T, Thomsen PD, Fair $\mathrm{T}$, et al. Effect of the post-fertilization culture environment on the incidence of chromosome aberrations in bovine blastocysts. Biol Reprod 2004;71:1096-100.

[57] Bavister BD. Culture of preimplantation embryos: facts and artifacts. Hum Reprod Update 1995;1:91-148.

[58] Thompson JG, Allen NW, McGowan LT, Bell AC, Lambert MG, Tervit HR. Effect of delayed supplementation of fetal calf serum to culture medium on bovine embryo development in vitro and following transfer. Theriogenology 1998;49:1239-49.

[59] Vanroose G, Van Soom A, de Kruif A. From co-culture to defined medium: state of the art and practical considerations. Reprod Domest Anim 2001;36:25-8.

[60] Morton KM, Herrmann D, Sieg B, Struckmann C, Maxwell WM, Rath D, et al. Altered mRNA expression patterns in bovine blastocysts after fertilisation in vitro using flow-cytometrically sex-sorted sperm. Mol Reprod Dev 2007;74:931-40.

[61] Rizos D, Clemente M, Bermejo-Alvarez P, de La Fuente J, Lonergan P, Gutiérrez-Adán A. Consequences of in vitro culture conditions on embryo development and quality. Reprod Domest Anim 2008;43(Suppl 4):44-50.

[62] Wilson RD, Weigel KA, Fricke PM, Rutledge JJ, LeibfriedRutledge ML, Matthews DL, et al. In vitro production of Holstein embryos using sex-sorted sperm and oocytes from selected cull cows. J Dairy Sci 2005;88:776-82. 
[63] Pontes JH, Silva KC, Basso AC, Rigo AG, Ferreira CR, Santos $\mathrm{GM}$, et al. Large-scale in vitro embryo production and pregnancy rates from Bos taurus, Bos indicus, and indicus-taurus dairy cows using sexed sperm. Theriogenology 2010;74:1349-55.

[64] Nagy ZP, Sakkas D, Behr B. Symposium: innovative techniques in human embryo viability assessment. Non-invasive assessment of embryo viability by metabolomic profiling of culture media ('metabolomics'). Reprod Biomed Online 2008;17:502-7.

[65] Beebe LF, Bouwman EG, McIlfatrick SM, Nottle MB. Piglets produced from in vivo blastocysts vitrified using the Cryologic vitrification method (solid surface vitrification) and a sealed storage container. Theriogenology 2011;75:1453-8. 